\title{
National Telemental Health Responses to a Major Bushfire Disaster
}

\section{Short Title: Bushfire Disaster Telemental Health Responses}

Lennart Reifels, Bridget Bassilios, Jane Pirkis

Word count: 4,958

Number of tables: 3

The authors are affiliated with the Centre for Health Policy, Programs and Economics, Melbourne School of Population Health, University of Melbourne, Victoria, Australia. Correspondence: Lennart Reifels, Centre for Health Policy, Programs and Economics, Melbourne School of Population Health, University of Melbourne, Victoria 3010, Australia, e-mail: 1.reifels@ unimelb.edu.au. The evaluation was supported through funding from the Australian Government Department of Health and Ageing. No competing interests declared. 


\section{Summary}

Notwithstanding the promise of telemental health services to offer accessible and cost-effective avenues of service provision, very little is known about their application in disaster contexts. We present findings from the pilot evaluation of national telemental health services provided as part of the Australian Government response to the 2009 Victorian bushfires. Data sources including service provider reports and key informant interviews were analysed through basic descriptive and thematic analyses. Nature, scope and uptake of services are outlined and benefits and issues associated with service provision in a bushfire disaster context discussed. All national services, except for the callback service, experienced significant increases in uptake levels. Overall, national telemental health services provided a valuable addition to existing avenues for counselling and crisis support. Models and modalities underpinning service delivery and the integration of telemental health services within broader disaster response structures warrant particular consideration in strengthening their contribution in future disaster circumstances.

Keywords: Natural Disaster, Telemedicine, Mental Health Services, Telephone Hotlines, Disaster Planning 
Running head: BUSHFIRE DISASTER TELEMENTAL HEALTH RESPONSES

\section{Introduction}

In February 2009, a series of bushfires of hitherto unprecedented magnitude in Australian history devastated large parts of the state of Victoria. These fires directly affected 51 townships, destroyed more than 2,000 homes and resulted in the tragic loss of 173 lives. $^{1}$

Large scale natural disasters such as this can have a severe and wide ranging impact on the lives of affected people and communities. ${ }^{2-3}$ The impact of bushfire disasters is typically manifest in the destruction of the physical and natural environment, the resulting displacement of people from homes and communities, as well as the various adverse physical and mental health consequences associated with exposure to traumatic bushfire events. ${ }^{4-6}$ While resilience and natural recovery processes mediate the trajectory of individual disaster responses, the impact of exposure to disasters on mental health can either be mild, moderate or severe, as well as short term, enduring or variable over time. ${ }^{7}$ World Health Organization estimates of the anticipated increase in mental health problems following disaster are outlined in Table 1. People with existing mental health problems may experience new or exacerbated symptoms or relapses associated with either direct involvement in the bushfires or media coverage of the event.

\section{Insert Table 1 here}

In response to the Victorian bushfire disaster, the Australian Commonwealth Government in collaboration with the Victorian Government provided a mental health support package (the Response). A key component of this Response entailed the provision of telemental health services in support of the broader levels of distress within the wider population. These services included telephone-based crisis counselling and callback services, and to a lesser extent, internetbased and on-the-ground support. Services were provided by three national agencies, namely, 
Kids Helpline (BoysTown), MensLine Australia (Crisis Support Services) and Lifeline Australia. With a national scope, these services were intended to complement other existing avenues for telephone and face-to-face mental health support at state and local levels. ${ }^{8}$ This paper presents findings of the pilot evaluation of telemental health services provided as part of the Response.

In view of the significant potential of telemental health services to offer accessible, confidential and cost-effective avenues for service provision, ${ }^{9-13}$ very little evidence exists in relation to their application in disaster contexts. Types of remotely delivered health and mental health services in disaster contexts have included information hotlines, triage and referral services, clinical consultation, crisis counselling and e-therapy. These services were provided through mediums such as the telephone, email, internet, videoconferencing and mobile satellite technology. ${ }^{14-17}$ Prominent international initiatives have included LifeNet, a mental health information and referral hotline, ${ }^{18-19}$ crisis counselling on the basis of Psychological First Aid, ${ }^{20}$ both in response to the September 11, 2001 terrorist attacks, and psychological assistance for victims of Hurricane Katrina. ${ }^{21}$ The application of telehealth services in post-disaster contexts can also be fraught with challenges which may result from a breakdown of electricity supply and telecommunication infrastructure. ${ }^{14,22}$

This paper contributes to the scarce evidence base in relation to the implementation of telemental health services in disaster contexts. Its findings are therefore of particular significance to improving the contribution of telemental health services in future disaster circumstances. 


\section{Methods}

The summative evaluation of the telemental health response specifically sought to answer the following key questions: (1) What is the precise nature and scope of telephone-based counselling and callback services for consumers? (2) What is the level of uptake of telephonebased counselling and callback services for bushfire affected consumers? (3) What are the benefits and disadvantages of telephone-based counselling and callback services for bushfire affected consumers? and (4) What issues are associated with providing telephone-based counselling and callback services to bushfire affected consumers?

Data sources utilised to address evaluation questions included written service provider reports and key informant interviews. Four project-level reports (which included an independent evaluation of one project) and supplementary service use data on another project were analysed systematically. In addition, semi-structured interviews were conducted with six key informants from the three involved provider agencies and the Victorian Department of Health. Interviewees were queried about their experience of delivering bushfire services, including the factors that had aided and hindered delivery and suggestions for further improvement. Interviews were recorded and transcribed. Transcripts were analysed through a combination of basic descriptive (frequencies, percentages) and thematic analyses. 


\section{Results}

\section{Nature and scope of services}

All provider agencies built on existing national service structures and staff resources, which were mobilized and expanded in their capacity to respond to bushfire-related service demand. For completeness sake, it is noteworthy that to varying degrees the involvement of the three agencies in the Response also entailed the provision of additional support services such as: a) training and supervision for counselling staff; b) interagency networking and service promotion; c) upgrades to bushfire referral databases; d) on-the-ground counselling support for bushfire recovery centres and media organisations; and e) outreach to affected Victorian households. A brief synopsis of the nature and scope of telemental health services provided through the three bushfire projects follows.

The Kids Helpline (BoysTown) Victorian Bushfire Strategy was conducted between June 2009 and July 2010. This project involved a significant increase in counselling hours of 120 existing professional counselling staff operating from the national call centre in Brisbane, Queensland. The service provided specialised telephone, web and email counselling to young people (aged between 5-25 years), as well as parents and caregivers concerned about the impact of the fires on their children. Underpinned by Kids Helpline's existing counselling model, tertiary qualified staff received additional training in relation to trauma, loss and grief and the impact of disasters on target groups. As part of the project, a bushfire web portal with three micro-sites was set up to serve the online information and support needs of children, teens and adults affected by the fires. 
The MensLine Australia Bushfire Emergency Aftermath Rebuild (or Bushfire EAR) project was conducted between May 2009 and June 2010. The Bushfire EAR provided targeted telephone counselling support to men and women (aged 15 years and over) affected by the Victorian bushfires, as well as to families and friends of those affected, emergency service workers and volunteers. The project was operationalised through a 24 hour 7 days a week intake line and a linked telephone counselling callback service which enabled the provision of up to six 50-minute counselling sessions, 7 days a week between the hours of 10am and 10pm. The callback service was underpinned by the Skills for Psychological Recovery approach, as an intermediate secondary prevention model, and operated by four dedicated staff trained in the approach. The intake line was operated by the majority of the 45 counselling staff based at the national call centre in Melbourne, Victoria, who were briefed about the fires and trained in relation to trauma and grief issues.

As part of the bushfire response, Lifeline Australia enhanced the capacity of its national network of 42 telephone centres and 3,500 trained volunteer counsellors to provide crisis counselling to individuals who were emotionally distressed by the bushfires, suicidal, or in need of support during times of crisis. This service was available 24 hours a day from day one. In addition, two interactive web-based bushfire forums / chat site facilities were operated immediately after the bushfires and at the time of the anniversary. These professionally facilitated forums enabled individuals to share their experiences and discuss strategies for dealing with bushfire events. Additional online resources such as toolkits for people experiencing trauma, loss and grief were made available on the Lifeline webpage. 
Running head: BUSHFIRE DISASTER TELEMENTAL HEALTH RESPONSES

\section{Service uptake and caller characteristics}

Kids Helpline. An analysis of Kids Helpline contacts undertaken by the provider for the reporting period July 2009 to March 2010 demonstrated that the overall call volume and number of contacts from bushfire affected areas in Victoria was approximately twice as high as would have normally been expected during this period. Table 2 outlines the number of overall and counselling type contacts from bushfire affected regions between July 2009 and March 2010. On the basis of percentages of recorded contacts where the caller postcode was known, the total call volume was interpolated. This suggested that out of the interpolated total of 3,951 contacts during the reporting period approximately 978 contacts involved dedicated counselling.

\section{Insert Table 2 here}

The majority of contacts were made via the telephone (60-67\%) with the remainder taking place through either real-time web-counselling (16-20\%) or email (13-22\%). 'Difficulties in managing challenging emotions and behaviours' featured as the strongest reason for making contact with the service (accounting for $25.6 \%$ of counselling contacts at the start of the reporting period). 'Mental health issues' featured as the strongest reason at the end of the reporting period (with $23.3 \%$ of counselling contacts). Other prominent reasons included 'family relationships', 'sexual assault' and 'relationship with peers'. Of the young callers from affected regions, 24-35\% were reportedly engaged in self injuring behaviours and 9-17\% had current thoughts of suicide at various intervals during the reporting cycle. The majority of callers were female (>74\%), aged between 15-25 years, and from Caucasian backgrounds. Of the counselling type contacts, 6-18\% involved a referral to a specialised service and 11-13\% a non-specific referral to a GP or school counsellor. 
Running head: BUSHFIRE DISASTER TELEMENTAL HEALTH RESPONSES

As an indication of the uptake of web-based resources, it was reported that during the quarter around the time of the anniversary alone (January to March 2010) there were: 775 hits to the Kids Helpline Victorian Bushfire teen micro site, 86 hits to the kids micro site, 55 hits to the adult micro site, and 28 hits to a site containing bushfire tip sheets.

MensLine Australia. During the reporting period of July 2009 to May 2010, MensLine's Bushfire EAR service recorded a total of 106 incoming calls, 59 outgoing calls and nine callback clients. Thirteen additional calls were received between May and June 2009.

The consumer profile was evenly balanced in terms of gender (49\% male, $44 \%$ female, rest unknown) with the majority aged between 35-64 years. While the geographical origin of calls was known in less than half of the cases, available data indicated that $34.9 \%(n=37)$ of incoming calls were received from Victoria and a combined $8.5 \%(\mathrm{n}=9)$ of calls from South Australia, Queensland and the Northern Territory. A significant proportion of callers were either single or separated and a majority lived in temporary accommodation. The majority of calls related to physical and mental health issues $46.1 \%(\mathrm{n}=35)$ as well as inter-personal issues $36.8 \%$ $(\mathrm{n}=28)$. Additional issues included parenting 9.2\% $(\mathrm{n}=7)$, legal, material, financial $5.3 \%(\mathrm{n}=4)$ and safety issues $2.6 \%(n=2)$. Over half of the clients $(54 \%)$ were reported to have medium to high levels of distress. While $57 \%(n=94)$ of calls could be classified as 'engaged' a large proportion of $43 \%(n=71)$ of calls was reported to be 'non-engaged'. Of the total number of calls, $38.8 \%(n=64)$ related to counselling, $6.1 \%(n=10)$ to counselling and referral and $4.2 \%(n=7)$ to requests for information. A total of eighteen referrals were made by MensLine Australia counsellors to Counselling services $(n=8)$, Health services $(n=3)$, Housing and Accommodation $(n=2)$, Other services $(n=3)$, Drug and Alcohol services $(n=1)$ and Legal assistance $(n=1)$. 
Running head: BUSHFIRE DISASTER TELEMENTAL HEALTH RESPONSES

Lifeline Australia. Data was available on the number of calls recorded by the provider in relation to the category of 'Community Crisis or Disaster' for the period of October 2008 to September 2009 (Table 3). During this period, 205 calls were recorded for the state of Victoria and 414 calls nationally. A marked increase in call volume across most Victorian regions and nationally was evident during the months of February and March 2009. The timing of this peak and level of increase (accounting for nearly half of annual Victorian calls during February and another quarter of annual calls during March alone) would suggest that this reflected the impact of the February bushfires in Victoria. However, the increase in national call volume may have also partly been due to Lifeline support provided to victims of the 2009 Queensland floods which took place at around the same time.

\section{Insert Table 3 here}

Data available on the types of issues underpinning Lifeline calls in Victoria remained largely inconclusive. The only indication of the relative impact of the Victorian bushfires in this data could have potentially been evident in a slight increase and relative peak during the month of February 2009 for calls in relation to 'abuse and trauma' (i.e., 6.2\% vs. annual average of $3.7 \%)$ and to a lesser degree for calls in relation to 'adjustment and loss' (5.5\% vs. annual average of $4.5 \%$ ). All other issue categories showed no significant temporal variations relative to the fire events.

Provider interview data suggested that the first interactive online forum provided by Lifeline immediately after the bushfires was taken up well by the public whereas demand for the second online forum held at the time of the anniversary was not particularly high. 


\section{Benefits and disadvantages for consumers}

Key informant interview data revealed a number of benefits of telemental health services for bushfire affected consumers which primarily revolved around the nature of the service and the medium employed. Specific benefits identified included the availability of: a) a free service; b) quick response; c) a less confrontational medium which allowed for greater privacy and confidentiality; d) wide ranging access to phone and web-based services; e) after hour access; and f) additional online information.

Disadvantages of bushfire telemental health services identified by key informants predominantly related to the utility of the callback model and specific barriers to accessing telephone services. Specific disadvantages included: a) the limited suitability of the callback model for a large number of clients who were living in transitory circumstances, or who were either on the move or homeless; b) practical issues associated with destroyed infrastructure, disconnected phone lines, and out of range mobile phones in rural areas; c) high mobile phone call costs for ringing ' 13 numbers' (whereas local call costs apply to landlines), which may be problematic as people displaced by the bushfires are more likely to use mobile phones to contact services; d) fragmentary information about wider sources of support available; and e) grief, loss and helplessness among affected community members as distinct barriers to help seeking.

Beyond key informant data, there was no consumer data available that would have allowed a direct assessment of overall client benefits, outcomes and satisfaction levels. The only exception to this was limited data available on the callback service (through counsellor casenotes and client self reports) which suggested that four of the seven clients who eventually engaged in the service benefited positively from it. Data for other callback clients remained inconclusive. 
Data on consumer demographics and contact reasons further indicated that telephone services were accessible to broad segments of the population who were provided with support in relation to a wide range of issues. Additional information on the perspective of staff of bushfire recovery and community health centres and other agencies referring to one of the bushfire telephone services indicated that the service was perceived as helpful and conducive to recovery and that knowledge of its existence was in and of itself reassuring for agency staff and community.

\section{Issues associated with service provision}

Interviews and project reports highlighted several issues and barriers that to varying degrees had impacted on the provision of bushfire telemental health services. These mainly revolved around the nature of bushfire calls, the suitability of the callback model, but also service coordination and data collection issues.

The nature of bushfire calls varied considerably from regular crisis calls. Bushfire calls did not appear to follow identifiable patterns and generally reflected a vastly greater contextual diversity and problem complexity. The high levels of client distress encountered and the complexity of underpinning issues made intake calls often more difficult to manage and screening measures difficult to administer for counselling staff. Similarly, single session crisis calls were reported to be more intense, demanding and slightly longer in duration than regular calls to such services.

The existing evidence and results of an independent evaluation suggested that the callback service model was not ideally aligned with postdisaster community needs. On the one hand, counsellors had difficulty contacting consumers and converting intake calls into callback 
services. The low number and greater complexity of bushfire-service calls (amidst generic service calls) made the adoption of a new bushfire specific service model (underpinned by the Skills for Psychological Recovery approach) more difficult for service providers. Bushfire affected consumers, on the other hand, who were often living through rather chaotic and transitory circumstances were found to be unable to make the most of the structured callback model. Thus, resulting usage patterns indicated that the service was more readily utilised as a regular crisis service. There was further a suggestion that the concept and value of callback services was not fully understood in the wider community.

An initial lack of awareness on the part of national provider agencies of the broader bushfire response structures and locally relevant service and referral contexts had to be overcome through provider networking and active acquisition of related information. There was a suggestion that coordination and communication between Federal and State governments and provider agencies could have potentially been stronger. A need for stronger departmental briefing and feedback mechanisms was raised by providers, as was the scope for a more systematic approach to the collection and sharing of data on service demand and uptake between relevant departments, which can facilitate overall response planning.

Key informants also highlighted important factors which facilitated the delivery of services. These included: a) use of the existing platform of reputable service providers and telephone numbers; b) ready access to highly trained staff who are used to dealing with trauma and difficult issues (such as suicide and violence); c) a dedicated project officer role which assisted agencies in liaising with relevant services on-the-ground and in supporting counselling staff; d) valuable input from external experts; e) cross-promotion of telephone services among agencies; f) free advertising space provided by cinemas and the media; g) the role of bushfire 
Running head: BUSHFIRE DISASTER TELEMENTAL HEALTH RESPONSES

case managers in affected regions which facilitated service referral; and h) the overall high level of cooperation and goodwill between all agencies involved. 


\section{Discussion}

Findings of the evaluation should be interpreted in the light of several limitations. These included the limited scope and variable nature of the data (evident in small interview sample size, variable baseline and quality of service uptake data, and a lack of data on consumer outcomes and perspectives) all of which put limitations on a comprehensive assessment of the uptake and impact of bushfire telemental health services.

Despite these limitations, it would appear that all three federally funded telemental health services provided as part of the response experienced significant increases in overall service uptake levels in the wake of the Victorian bushfires. Call volume in relation to the callback service, however, remained very limited which may have partly been due to a lack of alignment of the structured callback model with transitory living circumstances in the aftermath of the disaster. Caller profiles and call characteristics further indicated that national telemental health services reached consumers from broad segments of the population (including from bushfire affected areas and to some extent other states).

Due to the existence of state-level telephone counselling and other mental health services, it is difficult to assess the relative contribution of national telemental health services as part of the overall response to the fires. However, the available evidence would suggest that national telemental health services provided a valuable addition to existing avenues for counselling and crisis support for bushfire affected consumers. 
Running head: BUSHFIRE DISASTER TELEMENTAL HEALTH RESPONSES

\section{Implications}

The evaluation of the bushfire response offered valuable lessons for the planning of future disaster mental health responses and for enhancing the contribution of telemental health services in the wake of natural disasters.

\section{Callback services}

The evidence would suggest that while callback services may not be ideally suited as the primary platform for telemental health service provision in natural disaster contexts, they may have some merit as an adjunct to general crisis-type telephone services. Further education around the specific concept of callback services both in the community and among referring agencies can assist in increasing overall uptake levels.

\section{Service models, modalities and access}

Existing psychological support models underpinning post-disaster service delivery (such as Skills for Psychological Recovery) may benefit from a review and refinement in relation to the telephone modality and complex nature of client calls. In this context it is interesting to note that related international initiatives, albeit not identical in nature, adopted the Psychological First Aid approach ${ }^{20,21}$ which is aimed at a lower level of intervention. ${ }^{23}$ Counselling staff clearly benefit from training and support relating to the adoption of new service models, as from specific briefings in disaster mental health which can highlight the impacts of disaster-level trauma on individuals and communities.

Public access to telemental health services in the event of future disasters can further be improved through: a) enhancing telecommunication infrastructure (i.e., mobile phone coverage 
and broadband access) in rural and disaster-prone areas; b) a stronger focus on online and webbased forms of service provision (such as real-time web- and email-counselling) which proved useful in work with younger generations; and c) a review of existing costing models governing mobile phone calls to disaster telemental health services.

\section{Service coordination}

Several strategies proposed by key informants have the potential to strengthen overall levels of service coordination and the integration of national telemental health services within broader disaster response structures. These include: a) the establishment of a disaster response information clearinghouse; b) ready provider access to central response coordinators who should be familiar with relevant mental health services and disaster resources at local, state and national levels; c) ongoing departmental briefing mechanisms and updates for provider agencies; and d) forums in which federally-funded telemental health and relevant state-funded services can liaise and collaborate. The sharing of data between state and federal governments and the will to harness learning about emerging patterns of service demand and uptake were highlighted as important considerations in the planning of future disaster responses. The integration of disaster specific telehealth services within existing mainstream service structures can maximise their sustainability and utility for the broader population, as well as preparedness and capacity for future disaster circumstances. ${ }^{14,16}$ 


\section{Conclusion}

Preliminary evidence suggests that national telemental health services offered as part of the Response to the Victorian bushfires provided a valuable addition to existing avenues of counselling and crisis support. While structured callback models may be of limited utility in the

direct disaster aftermath, there is a need to support counselling staff and refine existing models of service delivery vis-a-vis the evidently more complex nature of client calls in disaster scenarios. The integration of telemental health services within existing mainstream services and wider disaster response structures warrants particular consideration in the future in order to optimise the contribution of telemental health services as viable and complementary components of disaster responses. 
Running head: BUSHFIRE DISASTER TELEMENTAL HEALTH RESPONSES

\section{Acknowledgements}

The evaluation was supported through funding from the Australian Government

Department of Health and Ageing. The authors wish to thank the Australian Government Department of Health and Ageing, the Victorian Department of Health, Kids Helpline (BoysTown), MensLine Australia (Crisis Support Services) and Lifeline Australia for their valuable input and insights. 
Running head: BUSHFIRE DISASTER TELEMENTAL HEALTH RESPONSES

\section{References}

1. Victorian Government Department of Human Services. After the Bushfires: Victoria's Psychosocial Recovery Framework. Melbourne: Victorian Government Department of Human Services, 2009

2. Ursano RJ, Fullerton CS, Weisaeth L, Raphael B. Individual and community responses to disasters. In: Ursano RJ, Fullerton CS, Weisaeth L, Raphael B, eds. Textbook of Disaster Psychiatry. Cambridge: University Press, 2007

3. Norris FH, Friedman MJ, Watson P. 60,000 disaster victims speak: Part II. Summary and implications of the disaster mental health research. Psychiatry 2002;65(3):240-60

4. Laugharne J, Van de Watt G, Janca A. After the fire: The mental health consequences of fire disasters. Curr Opin Psychiatry 2011;24(1):72-7

5. Cameron PA, Mitra B, Fitzgerald M, et al. Black Saturday: The immediate impact of the February 2009 bushfires in Victoria, Australia. Med J Aust 2009;191(1):11-6

6. Camilleri P, Healy C, Macdonald E, et al. Recovering from the 2003 Canberra Bushfire: A Work in Progress. Report Prepared for Emergency Management Australia. Australian Catholic University, 2007 
Running head: BUSHFIRE DISASTER TELEMENTAL HEALTH RESPONSES

7. Van Ommeren M. Inter-Agency Standing Committee (IASC) Guidance on Mental Health and Psychosocial Support in Emergency Settings. Public Health Pre-Deployment Training. Chavannes de Bogis, Switzerland, 2006

8. Better Health Channel. Victorian Counselling Services Available During Bushfire Crisis. www.betterhealth.vic.gov.au, 2010 (last accessed 03-02-2010)

9. Leach LS, Christensen H. A systematic review of telephone-based interventions for mental disorders. J Telemed Telecare 2006;12(3):122-9

10. Postel MG, de Haan HA, de Jong CAJ. E-therapy for mental health problems: A systematic review. Telemed J E Health 2008;14(7):707-14

11. Bee P, Bower P, Lovell K, et al. Psychotherapy mediated by remote communication technologies: A meta-analytic review. BMC Psychiatry 2008;8(1):60

12. Hilty DM, Marks SL, Urness D, Yellowlees P, Nesbitt TS. Clinical and educational telepsychiatry applications: A review. Can J Psychiatry 2004;49(1):12-23

13. Schoenbaum M, Butler B, Kataoka S, et al. Promoting mental health recovery after hurricanes Katrina and Rita: What can be done and at what cost. Arch Gen Psychiatry 2009;66(8):906-14 
Running head: BUSHFIRE DISASTER TELEMENTAL HEALTH RESPONSES

14. Merrell RC, Cone SW, Rafiq A. Telemedicine in extreme conditions: Disasters, war, remote sites. In: Latifi R, ed. Current Principles and Practices of Telemedicine and E-Health. IOS Press, 2008

15. Yellowlees P, Burke MM, Marks SL, Hilty DM, Shore JH. Emergency telepsychiatry. J Telemed Telecare 2008;14(6):277-81

16. Simmons S, Alverson D, Poropatich R, D'Iorio J, Devany M, Doarn CR. Applying telehealth in natural and anthropogenic disasters. Telemed J E Health 2008;14(9):968-71

17. Llewellyn CH. The role of telemedicine in disaster medicine. J Med Syst 1995;19(1):29-34

18. Wunsch-Hitzig R, Plapinger J, Draper J, Del Campo E. Calls for help after September 11: A community mental health hot line. J Urban Health 2002;79(3):417-28

19. Stolper G. New York: 9/11 and After. www.mha-nyc.org, 2003 (last accessed 17-01-2011)

20. Halpern J, Tramontin M. A case study: Psychological First Aid on the phone. In: Disaster mental health: Theory and practice. Belmont: Thomson, 2007

21. Combs DC. Mental health interventions by telephone with Katrina survivors. J Health Care Poor Underserved 2007;18(2):271-6 
Running head: BUSHFIRE DISASTER TELEMENTAL HEALTH RESPONSES

22. Merrell RC, Doarn CR. Disasters - How can telemedicine help? Telemed J E Health 2005;11(5):511-2

23. Australian Psychological Society. Guidelines for Provision of Psychological Support to People affected by the 2009 Victorian Bushfires. www.psychology.org.au, 2010 (last accessed 21-08-2011) 
Table 1: Summary of WHO prediction of the prevalence of psychosocial problems after an emergency

\begin{tabular}{llr}
\hline & $\begin{array}{c}\text { Before } \\
\text { emergency - }\end{array}$ & $\begin{array}{c}\text { After emergency - } \\
\text { 12-month } \\
\text { prevalence }\end{array}$ \\
& prevalence & 3-4\% \\
\hline Severe mental disorder (such as psychosis, severe & 2-3\% & 20\% (reduces to \\
depression, severe disabling anxiety disorder) & 10\% & 15\% with natural \\
\hline Mild or moderate mental disorder (such as mild and & recovery) \\
moderate depression or anxiety) & Adapted from Van Ommeren (2006) \\
\hline Moderate or severe psychological/social distress (no & No estimate & Large percentage \\
formal disorder but severe distress) & (reduces due to
\end{tabular}


Table 2: Overall and counselling type contacts from bushfire affected regions in Victoria (July 2009 to March 2010)

\begin{tabular}{lll}
\hline Reporting period & $\begin{array}{l}\text { Actual contacts } \\
\text { recorded }\end{array}$ & $\begin{array}{l}\text { Interpolated } \\
\text { contacts }\end{array}$ \\
\hline Jul-Sep 2009* & 121 & 1210 \\
Oct-Dec 2009** & 213 & 1420 \\
Jan-Mar 2010*** & 185 & 1321 \\
\hline Total & $\mathbf{5 1 9}$ & $\mathbf{3 9 5 1}$ \\
\hline & Actual counselling type & $\begin{array}{l}\text { Interpolated counselling } \\
\text { type contacts }\end{array}$ \\
\hline Jul-Sep 2009 & contacts recorded & 281 \\
\hline Oct-Dec $2009^{++}$ & 90 & 344 \\
\hline Jan-Mar 2010 & 165 & 353 \\
\hline Total & 159 & $\mathbf{9 7 8}$ \\
\hline NB. Postcode known in $* 10 \%, * * 15 \%, * * * 14 \%,{ }^{++} 32 \%,{ }^{++} 48 \%,{ }^{+++} 45 \%$ of contacts
\end{tabular}


Running head: BUSHFIRE DISASTER TELEMENTAL HEALTH RESPONSES

Table 3: Number of calls from Victorian centres with 'Community Crisis/Disaster' as an issue (October 2008 to September 2009)

\begin{tabular}{|c|c|c|c|c|c|c|c|c|c|}
\hline & 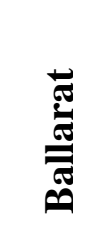 & 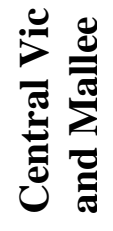 & 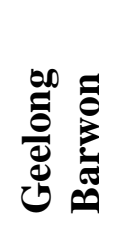 & $\frac{\bar{E}}{\frac{\vec{E}}{\bar{\omega}}}$ & 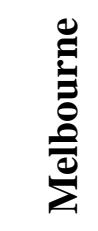 & 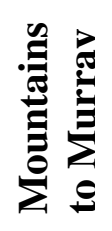 & 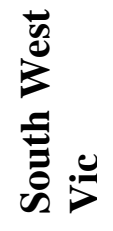 & 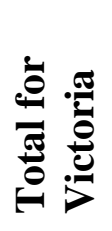 & 丞 \\
\hline $\begin{array}{l}\text { Oct } \\
2008\end{array}$ & 0 & 1 & 1 & 0 & 0 & 0 & 0 & 2 & 9 \\
\hline $\begin{array}{l}\text { Nov } \\
2008\end{array}$ & 0 & 0 & 0 & 0 & 1 & 0 & 0 & 1 & 13 \\
\hline $\begin{array}{l}\text { Dec } \\
2008\end{array}$ & 0 & 1 & 0 & 0 & 2 & 0 & 0 & 3 & 11 \\
\hline $\begin{array}{l}\text { Jan } \\
2009\end{array}$ & 1 & 0 & 1 & 1 & 6 & 0 & 0 & 9 & 24 \\
\hline $\begin{array}{l}\text { Feb } \\
2009\end{array}$ & 6 & 7 & 14 & 12 & 49 & 1 & 2 & 91 & 159 \\
\hline $\begin{array}{l}\text { Mar } \\
2009\end{array}$ & 2 & 3 & 7 & 5 & 24 & 3 & 0 & 44 & 84 \\
\hline $\begin{array}{l}\text { Apr } \\
2009\end{array}$ & 0 & 0 & 2 & 1 & 3 & 1 & 0 & 7 & 27 \\
\hline $\begin{array}{l}\text { May } \\
2009\end{array}$ & 0 & 0 & 1 & 3 & 2 & 1 & 0 & 7 & 14 \\
\hline $\begin{array}{l}\text { Jun } \\
2009\end{array}$ & 0 & 0 & 0 & 0 & 9 & 0 & 0 & 9 & 19 \\
\hline $\begin{array}{l}\text { Jul } \\
2009\end{array}$ & 0 & 0 & 0 & 4 & 2 & 1 & 0 & 7 & 14 \\
\hline $\begin{array}{l}\text { Aug } \\
2009\end{array}$ & 0 & 1 & 3 & 5 & 5 & 0 & 0 & 14 & 21 \\
\hline $\begin{array}{l}\text { Sep } \\
2009\end{array}$ & 2 & 0 & 0 & 3 & 6 & 0 & 0 & 11 & 19 \\
\hline Total & 11 & 13 & 29 & 34 & 109 & 7 & 2 & 205 & 414 \\
\hline
\end{tabular}

